\title{
Calibration of Activated Sludge Model with Scarce Data Sets
}

\author{
Dariusz Andraka1*, Iwona Kinga Piszczatowska², Jacek Dawidowicz', \\ Wojciech Kruszyński ${ }^{1}$
}

1 Białystok University of Technology; Faculty of Civil and Environmental Engineering; Wiejska 45E, 15-351 Bialystok; Poland

2 Wodociągi Białostockie (Bialystok Water Supply) Sp. z o.o., Młynowa 52/1, 15-590 Białystok, Poland

* Corresponding author e-mail: d.andraka@pb.edu.pl

\begin{abstract}
Mathematical models of activated sludge process are well recognised and widely implemented by researchers since 1980's. There is also numerous software available for modelling and simulation of activated sludge plants, but practical application of those tools is rather limited. One of the main reasons for such a situation is a difficult process of model calibration the requires extended data sets collected at investigated plant. Those data are usually not included in a standard plant monitoring plan. In the paper the problem of model calibration with the data sets derived from standard monitoring plan is discussed with a special regard to simulation objectives and data availability. The research was conducted with operational data from Białystok Wastewater Treatment Plant. The model of the plant was based on Activated Sludge Model No.3 developed by IWA Task Group and implemented in ASIM simulator. Calibration and validation of the model gave promising results, but further applications should be carefully considered, mainly due to uncertainties underlying input data.
\end{abstract}

Keywords: activated sludge models, modelling and simulation, model calibration

\section{INTRODUCTION}

Mathematical models of activated sludge process have been widely used by researchers and professionals for more than three decades. A task group formed in 1982, under the auspices of IWA (then the International Association on Water Pollution Research and Control) had a major contribution to the development of activated sludge models (ASM). The first model elaborated by the group came to be known as Activated Sludge Model No. 1 (ASM1) (Henze et al. 1987) and was followed by next generation models, including: ASM2 and ASM2d (Henze et al. 1995, 1999) and ASM3 (Gujer et al. 1999). Moreover, other researchers contributed to the development of activated sludge models, These include especially the Barker and Dold model (1997), as well as extension to ASM3 model developed by Riegger et al. (2001), both of which cover the biological phosphorus removal process.
With recent developments in IT (especially the popularization of powerful personal computers), the commercial software (simulators) that implements the above-mentioned mathematical models, became available. These simulators usually contain additional models for other unit processes (primary and secondary settlers, anaerobic digestion, thickening and dewatering), enabling simulation of the whole treatment facility (Rieger et al. 2013). In addition to commercial simulators, one can also find a few freeware tools, which are typically available for download (ASIM, STOAT $®$ ) or are Web-based and intended to be run through a Web-based application (JASS). The key aspects to consider while planning to use freeware tools are: limited functionality, less flexible user interface, and what can be deciding for less experienced modelers - the lack of support (WEF MOP31 2014).

As reported by Hauduc et al. (2009), Universities, public research centers and private con- 
sulting / engineering companies represent the majority of ASM users while only few of them are related with wastewater treatment plants (WWTPs). The main obstacles limiting modeling projects, expressed by the respondents of this survey, can be split into 4 topics: cost and time demand; model structure (complexity, reliability and non-adequacy of models); model application (for many potential users - models are not required to reach their objectives) and modeling procedure (data collection, calibration and validation, etc.). Particularly strong obstacles for the potential users from WWTPs are: costs and ASM complexity, related with large number of unit processes building the model, which are described by even more kinetic and stoichiometric parameters. These parameters can be evaluated from different information sources (Petersen et al., 2002):

- default parameter values from literature (usually used as defaults in built-in models of the simulators);

- full-scale facility data (average or dynamic data from collected samples, online data, measurements in reactors to characterize process dynamics);

- bioassays tests (laboratory-scale experiments with wastewater and activated sludge from the full-scale facility under study).

The parameter values obtained from defaults through fitting the model until simulation results agree sufficiently with the facility data are known as calibrated parameters, while those evaluated directly from measurements and experiments are referred to as measured parameters. In order to obtain reliable results, researchers use both types of parameters, which requires establishing special monitoring plan for the studied WWTP because routinely performed analyses of typical parameters characterizing influent and effluent (BOD, TSS, total nitrogen and phosphorus) are not consistent with the purpose of modeling and model requirements.

In most cases, the data available from historical records pertaining to monitoring results of the wastewater treatment facility include only the basic parameters (BOD, COD, TSS, TN, TP), which cannot be used directly for modeling purposes. As the result, there are few examples in the literature where plant operational data collected during standard monitoring plan were used as model input (Cinar et al., 1998; Sochacki et al., 2009) and practical applications of ASM are the few.
The main purpose of this study was to check the applicability of limited data sets obtained during routine monitoring of municipal WWTP in Białystok (Poland) for the calibration and validation of WWTP model under static conditions and to evaluate the possible application areas of such a simplified model.

\section{MATERIALS AND METHODS}

\section{Bialystok WWTP characterization}

Municipal wastewater treatment plant in Bialystok was constructed in 1974 for a design flow rate of $176.500 \mathrm{~m}^{3} / \mathrm{d}$. In 2002, the facility was significantly reconstructed in order to achieve higher efficiency of biogenic compounds elimination (to comply with compulsory regulations), and the capacity of the plant was reduced to $100.000 \mathrm{~m}^{3} / \mathrm{d}$ (Simson, 2008). The technological layout of the facility consists of the following sections: preliminary mechanical treatment (screens, rectangular aerated grit chambers with sand separator, primary settlers with horizontal flow), biological reactors with activated sludge, comprising: predenitrification $(\mathrm{PreDN})$ and anaerobic (DeP) sections organized in 4 parallel lines and anoxic (denitrification, DN) - aerobic (nitrification, $\mathrm{N}$ ) sections organized into 8 parallel lines (with total volume $\mathrm{V}_{\mathrm{B}}=63.200 \mathrm{~m}^{3}$ ) and six parallel secondary clarifiers $\left(6.000 \mathrm{~m}^{3}\right.$ each). At present, PreDN and DeP (dephosphatation) basins (which are reconstructed from old primary settlers, with volume of $1.800 \mathrm{~m}^{3}$ each) work only in 2 (out of 4) lines. They receive return activated sludge (RAS) from secondary clarifiers which can be split between PreDN and DeP with ratio 30/70\%. The RAS flow is varying between $150-300 \%$ of daily inflow to the plant. Main activated sludge reactors form two technological blocs with different type of aeration (surface aerators and diffused air aerators). Each of 8 parallel lines consists of 3 sections: anoxic (DN, volume $1.375 \mathrm{~m}^{3}$ ), alternative (either anoxic or aerobic, volume $1.125 \mathrm{~m}^{3}$ ) and aerobic $\left(\mathrm{N}\right.$, volume $4500 \mathrm{~m}^{3}$ ). Thus, the aerated volume makes up $60-75 \%$ of the total biological reactor's volume, depending on the state of the alternating section. The rate of internal recirculation of nitrate-rich mixture from aerobic to anoxic section is varying between $400-600 \%$ of daily inflow to the plant. In addition to biological phosphorus uptake, the facility is equipped with an installation for chemical precipitation of phosphates. 
The Bialystok WWTP provides high efficiency of organic matter, solids and phosphorus removal, while nitrogen compounds elimination is unsteady (Table 1). For this reason, after a series of pilot studies (Simson, 2008; Ignatowicz et al., 2015), an installation for dosing external carbon source was introduced in 2009. Different agents are used for this purpose (with carbon content measured as COD no less than $1.000 .000 \mathrm{~g} / \mathrm{m}^{3}$ ) with the rate of 40-70 g per $1 \mathrm{~m}^{3}$ of sewage inflow.

For the purpose of this study, only routine operational data, collected within standard monitoring plan of the facility, were used. In the Bialystok WWTP, the data, including raw and mechanically treated sewage, as well as effluent from the plant characteristics, are collected two times a month, which meets the requirements of applicable environmental regulations. The yearly averages estimated from the acquired data are presented in Table 1.

\section{Modeling procedure}

Together with the introduction of different simulators, several modeling protocols were pub- lished with the aim to guide model users through a series of defined steps and to obtain reliable results with less effort. However, the most popular protocols often presented different approach to modeling. STOWA protocol (Hulsbeek et al., 2002; Roeleveld and van Loosdrecht, 2002) was developed in order to help with modeling nitrogen removal using ASM No.1 model. On the other hand, the WERF guidelines (Melcer et al., 2003) were based on the experience with ASM from consulting companies, software developers and universities, mainly from North America) with targeted users from municipalities and consulting engineering companies. The BIOMATH protocol (Vanrolleghem et al., 2003) introduced a concept of step-wise calibration/validation of models, with a focus on the biokinetic model and sections on settling, hydraulics, and aeration. The HSG protocol (Langergraber et al., 2004) gathered the experience of researchers from German-speaking countries and encourages an objective-oriented approach. In order to bridge the gap between the existing protocols, a new IWA task group was formed - Good Modeling Practice (GMP) Task Group - with the aim to combine these proto-

Table 1. Wastewater characteristics of Białystok WWTP based on operational data

\begin{tabular}{|c|c|c|c|c|c|c|c|c|}
\hline \multirow{2}{*}{ Parameter } & Flow & BOD5 & COD & TSS & $\mathrm{TN}$ & $\mathrm{N}-\mathrm{NH} 4$ & TP & temp. \\
\hline & $\mathrm{m}^{3} / \mathrm{d}$ & $\mathrm{mg} / \mathrm{dm}^{3}$ & $\mathrm{mg} / \mathrm{dm}^{3}$ & $\mathrm{mg} / \mathrm{dm}^{3}$ & $\mathrm{mg} / \mathrm{dm}^{3}$ & $\mathrm{mg} / \mathrm{dm}^{3}$ & $\mathrm{mg} / \mathrm{dm}^{3}$ & ${ }^{\circ} \mathrm{C}$ \\
\hline \multicolumn{9}{|c|}{2016 - Influent (raw sewage) } \\
\hline Average & - & 443 & 1142 & 591 & 88 & - & 11.7 & - \\
\hline MIN & - & 200 & 629 & 390 & 38.3 & - & 6.2 & - \\
\hline MAX & - & 800 & 1600 & 930 & 147 & - & 26.8 & - \\
\hline \multicolumn{9}{|c|}{2016 - After mechanical pretreatment } \\
\hline Average & - & 240 & 455.4 & 77.1 & 63 & 46.5 & 5.2 & - \\
\hline MIN & - & 140 & 312 & 50 & 46.2 & 37.9 & 2.6 & - \\
\hline MAX & - & 390 & 588 & 97 & 82.5 & 58.7 & 7.3 & - \\
\hline \multicolumn{9}{|c|}{$2016-$ Final effluent } \\
\hline Average & 66.430 & 3.7 & 31 & 4 & 8.7 & - & 0.3 & 15.2 \\
\hline MIN & 45.900 & 1.9 & 20 & 2 & 5.0 & - & $<0.2$ & 10.5 \\
\hline MAX & 114.600 & 5.6 & 52 & 11 & 13.2 & - & 0.83 & 20.7 \\
\hline \multicolumn{9}{|c|}{2017 - Influent (raw sewage) } \\
\hline Average & - & 485 & 1193 & 748 & 78.1 & 43.6 & 9.93 & 14.2 \\
\hline MIN & - & 170 & 557 & 170 & 51.1 & 30.5 & 6.02 & 6.6 \\
\hline MAX & - & 1020 & 2600 & 1860 & 113 & 55.6 & 16.8 & 18.5 \\
\hline \multicolumn{9}{|c|}{2017 - After mechanical pretreatment } \\
\hline Average & - & 165.5 & 331.2 & 63.7 & 49.4 & 39.2 & 3.97 & - \\
\hline MIN & - & 77 & 192 & 36 & 26.7 & 18.5 & 1.8 & - \\
\hline MAX & - & 260 & 444 & 87 & 67 & 54.5 & 3.5 & - \\
\hline \multicolumn{9}{|c|}{$2017-$ Final effluent } \\
\hline Average & 73.693 & 2.8 & 27.7 & 3.3 & 10.15 & - & 0.3 & 14.6 \\
\hline MIN & 54.500 & 1.2 & 20 & 2.0 & 7.6 & - & 0.2 & 5.8 \\
\hline MAX & 108.400 & 4.2 & 42 & 7.3 & 14.6 & - & 0.55 & 20.8 \\
\hline
\end{tabular}

Symbols: BOD5 - 5-day Biochemical Oxygen Demand; COD - Chemical Oxygen Demand; TSS - Total Suspended Solids; TN - total nitrogen; N-NH4 - Ammonia Nitrogen; TP - Total Phosphorus 
cols in one unified protocol intended mainly for practitioners. This unified protocol comprises following steps (Rieger et al., 2012): 1 - project definition; 2 - data collection and reconciliation; 3 - plant model setup; 4 - calibration and validation, 5 - simulation and results interpretation.

In the project definition step, the problem related with modeling task should be formulated and then - objectives of the project defined together with determination of requirements. In this study, after the analysis of the Bialystok WWTP performance it was decided that the main objective of modeling project will be the simulation of nitrogen removal processes in the plant.

Data collection and reconciliation aims at the preparation of reliable data sets for simulation projects, using dedicated methods based on statistical analysis, expert knowledge etc. According to the preliminary assumptions, only the data from routine plant monitoring were used in this study. The collected data were analyzed in order to eliminate outliers and detect possible faults in measurements and reports.

Plant model was created using ASIM simulator (Holinger, http://www.holinger.com). The main reasons for this choice were the software availability (it is free for noncommercial applications) and the ease of application for basic technological layouts of biological treatment units, which could promote its usage by less experienced modelers. Although ASIM allows only for the simulation of biological treatment systems (without preliminary treatment or sludge disposal processes) it has built-in IWA basic models: ASM No.1, ASM No.2d and ASM No.3 that may be freely edited, redefined and stored by the user. Since nitrification and denitrification processes were the main focus of this study, ASM1 and ASM3 were taken into account for the simulation. After preliminary investigations, ASM3 was selected for further simulations due to following premises:

- influent fractionation in ASM3 is relatively easier than in ASM1, which may be essential in the case of limited input information;

- although ASM3 includes significantly more unit processes than ASM1 (12 vs 7), as well as stoichiometric (7 vs 3 ) and kinetic (21 vs 14 ) parameters, the complexity of both models is comparable; furthermore, ASM3 is designed to be the core of many different models (for example modules on phosphorus removal can be easily connected) and to satisfy primarily the requirements of practical model applications (Henze et al. 2000);

- initial simulations with default parameters showed better results for ASM3, especially in terms of the response of the model to temperature changes, which was essential for the examined WWTP, as the nitrogen removal efficiency strongly depends on the seasonal variations in wastewater temperature.

The plant model created with ASIM simulator is presented in Figure 1. In order to simplify the modeling, procedure only one technological line was imitated in the model. Assuming that wastewater after mechanical pretreatment is homogeneously mixed with RAS and then is evenly distributed between 8 parallel lines, the model represents the average conditions in the biological part of the plant. It is also important to note that due to the software limitations it was impossible to represent all bioreactors with their specifics in one model.

For the calibration and validation of the model, operational data were grouped in two data sets representing monthly averages of measured parameters: a) calibration data set from the period February - September, 2016, and b) validation data set for the period January - July, 2017. The sensitivity analysis was performed according to EPA guidelines (US EPA, 1987) to determine the parameters that may influence the model behavior significantly. The normalized sensitivity coefficients were evaluated with the following formula:

$$
S_{i, j}=\frac{\Delta y_{j} / y_{j}}{\Delta x_{i} / x_{i}}
$$

where: $\Delta y_{j}$ - increase in output variable (for example $\mathrm{N}-\mathrm{NH}_{4}, \mathrm{TN}$ etc.) relevant to $\Delta x_{\mathrm{i}}$ increase in input variable (for example stoichiometric or kinetic parameter of the model).

For the purpose of this research, a $10 \%$ increase in input variables was applied, as suggested by Liwarska-Bizukojc and Biernacki (2010). According to Petersen et al. (2003), the coefficients $S_{\mathrm{i}, \mathrm{j}}<0.25$ have no significant influence on the model, while $1<S_{\mathrm{i}, \mathrm{j}}<2$ are very influential and $S_{i, j}>2$ are extremely influential.

The calibrated values of influential parameters were obtained using a goodness-of-fit test, based 


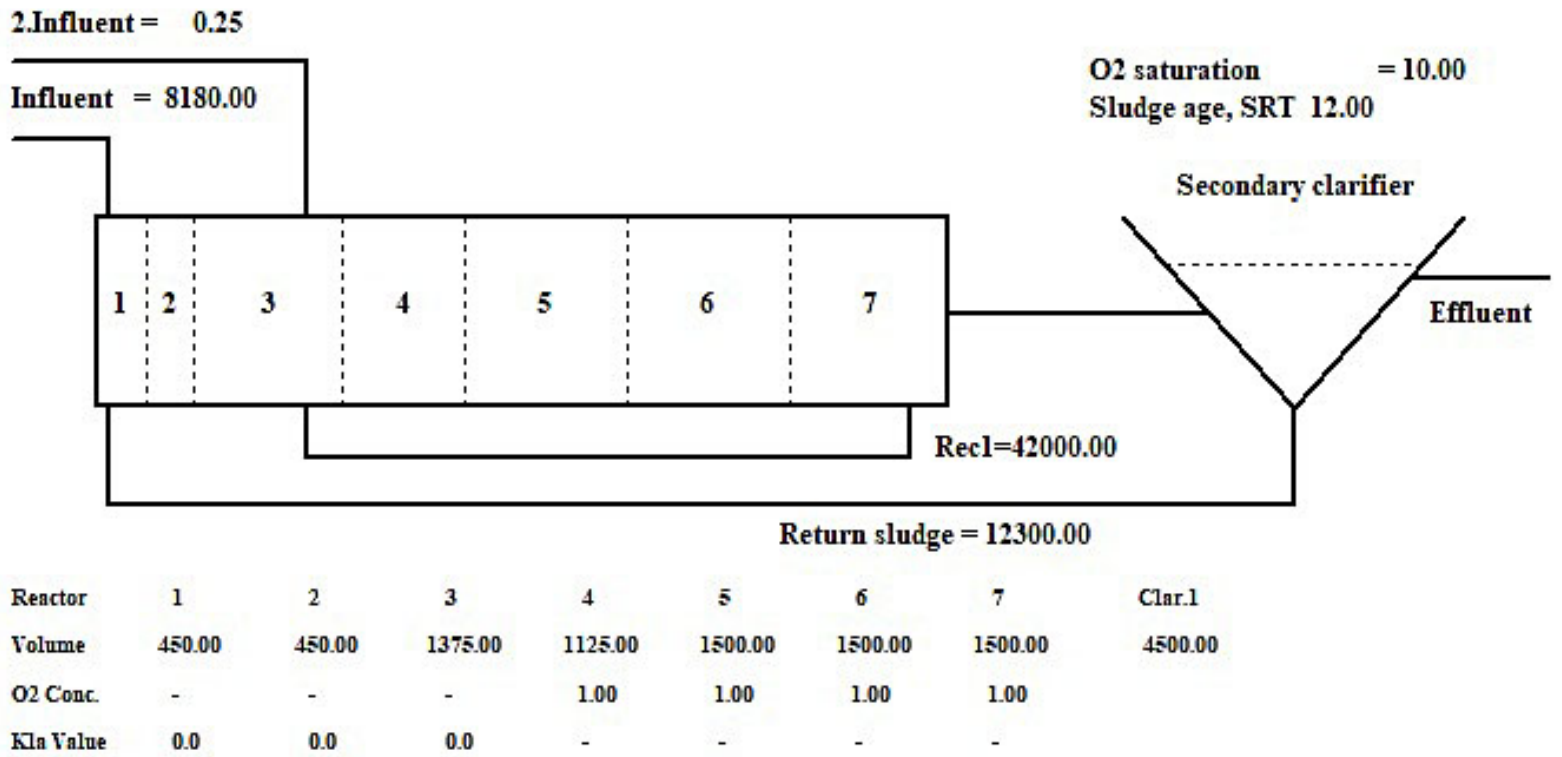

Figure 1. Example of Bialystok WWTP model in ASIM simulator (data on the diagram - April, 2016)

on absolute criterion from residuals, calculated from following formula (WEF MOP31, 2014):

$$
E_{2}=\frac{1}{n} \sum_{i=1}^{n}\left(O_{i}-P_{i}\right)^{2} \rightarrow \min
$$

where: $O_{i}-$ observed value;

$P_{i}$ - simulated value;

$n$ - number of simulations.

\section{RESULTS AND DISCUSSION}

The application of ASM requires influent fractionation according to input data structure for a given model. As the influent data available for this study did not include the information about COD fractions, it was necessary to estimate the input variables on the basis of preliminary simulations. The plant model was created using yearly average inflow characteristics and default parameters values. The simulation results were compared with the yearly average effluent quality and relevant parameters were adjusted to obtain acceptable agreement. The default and adjusted fractionation parameters are presented in Table 2.

The calibration procedure was performed with regard to the study goals. Since the target process of this research was nitrogen compounds removal, the calibration data set was prepared consisting of monthly averages for the period FebruarySeptember, 2016. Moreover, the stop criterion

Table 2. Comparison of ASM3 model compounds for typical wastewater composition (Henze, 2000) and Bialystok WWTP (primary efluent)

\begin{tabular}{|c|c|c|c|c|c|c|c|c|}
\hline \multirow{3}{*}{ Compounds } & \multicolumn{3}{|c|}{ Dissolved compounds } & \multicolumn{5}{|c|}{ Particulate compounds } \\
\hline & $S_{1}$ & $\mathrm{~S}_{\mathrm{s}}$ & $\frac{S_{S}}{S_{C O D}}$ & $X_{1}$ & $X_{s}$ & $X_{H}$ & $\frac{X_{S}}{X_{C O D}}$ & $\frac{X_{H}}{X_{C O D}}$ \\
\hline & \multicolumn{2}{|c|}{$\mathrm{gCOD} / \mathrm{m}^{3}$} & - & \multicolumn{3}{|c|}{$\mathrm{gCOD} / \mathrm{m}^{3}$} & - & - \\
\hline \multirow[b]{2}{*}{ Typical } & 30 & 60 & 0.60 & 25 & 115 & 30 & 0.69 & 0.10 \\
\hline & \multicolumn{8}{|c|}{$\begin{array}{l}\mathrm{COD}_{\text {tot }}=260 \mathrm{gCOD} / \mathrm{m}^{3} ; \mathrm{TSS}=125 \mathrm{gSS} / \mathrm{m}^{3} ; \mathrm{TSS} / \mathrm{X}_{\mathrm{COD}}=0.75 ; \mathrm{TKN}=25 \mathrm{gN} / \mathrm{m}^{3} ; \mathrm{S}_{\mathrm{NH} 4}=16 \mathrm{gN} / \mathrm{m}^{3} \\
\mathrm{~S}_{\mathrm{NH} 4} / \mathrm{TKN}=0.64\end{array}$} \\
\hline \multirow[b]{2}{*}{ Bialystok WWTP } & 29 & 234 & 0,89 & 40 & 133 & 19 & 0,69 & 0,1 \\
\hline & \multicolumn{8}{|c|}{$\begin{array}{l}\mathrm{COD}_{\text {tot }}=455 \mathrm{gCOD} / \mathrm{m}^{3} ; \mathrm{TSS}=77 \mathrm{gSS} / \mathrm{m}^{3} ; \mathrm{TSS} / \mathrm{X}_{\mathrm{COD}}=0.40 ; \mathrm{TKN}=63 \mathrm{gN} / \mathrm{m}^{3} ; \mathrm{S}_{\mathrm{NH} 4}=46 \mathrm{gN} / \mathrm{m}^{3} ; \\
\mathrm{S}_{\mathrm{NH} 4} / \mathrm{TKN}=0.73\end{array}$} \\
\hline
\end{tabular}

Symbols: $\mathrm{S}_{\mathrm{I}}-$ soluble inert organics, $\mathrm{S}_{\mathrm{S}}-$ readily biodegradable substrates; $\mathrm{S}_{\mathrm{COD}}-$ soluble COD; $\mathrm{S}_{\mathrm{NH} 4}-$ ammonium; $\mathrm{X}_{\mathrm{I}}$ - inert particulate organics; $\mathrm{X}_{\mathrm{S}}$ - slowly biodegradable substrates; $\mathrm{X}_{\mathrm{H}}-$ heterotrophic biomass; $\mathrm{X}_{\mathrm{COD}}-$ particulate COD; $\mathrm{COD}_{\text {tot }}$ - total COD; TSS - total suspended solids; TKN - total Kiejdahl nitrogen 


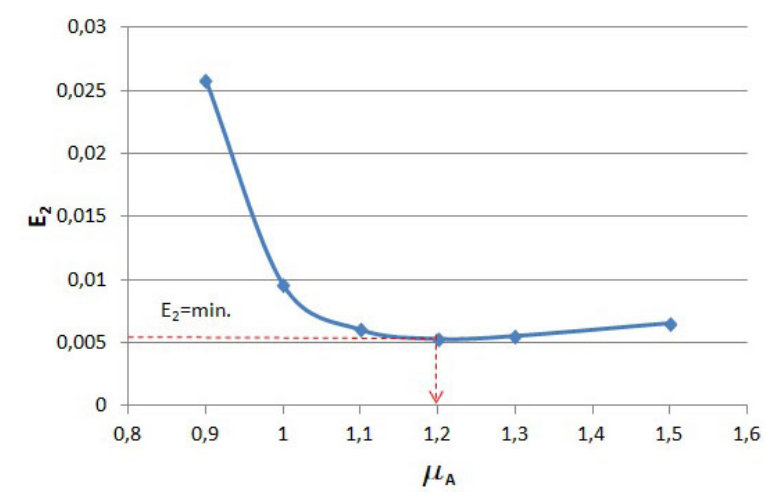

Figure 2. Calibration of autotrophic maximum growth rate (uA) by minimization of absolute criterion from residuals $(\mathrm{E} 2)$

(acceptable error range) was established, according to Rieger et al. (2012) at value of $1.0 \mathrm{gN} / \mathrm{m}^{3}$.

The initial run of the model was performed with default stoichiometric and kinetic parameters, built in ASIM simulator. The comparison of simulated and observed values indicated that the acceptable error range was exceeded in several points (compare Figure 3, series TN(1) and TN(2) for IV.2016, V.2016, VI.2016 and VIII.2016) and further parameters calibration is required. The analysis performed with Eq. (1) for the model parameters responsible for nitrogen removal allowed for determination of influential parameters, which were adjusted afterwards by minimization of average squared residuals $\left(E_{2}\right)$ with Eq. (2). The graphical representation of the calibration process for autotrophic maximum growth rate $\left(\mathrm{m}_{\mathrm{A}}\right)$ is shown in Figure 2 and the summary of calibration results for all influential parameters is presented in Table 3.
The data presented in Table 3 partly correspond with the results of Hauduc et al. studies (2011), presented later in Rieger et al. (2012) who examined several databases for ASM3 models of full scale WWTPs in Northern Europe and proposed new default parameter set, including autotrophic maximum growth rate $\left(\mathrm{m}_{\mathrm{A}}\right)$ at the value of $1,3 \mathrm{~d}^{-1}$.

The simulation results for ASM3 default and calibrated model, compared with the observed values of total nitrogen in the effluent from the plant are presented in Figure 3.

The obtained results show that in most cases, the calibrated ASM3 model has better accuracy of predictions than the default model and only in the case of June, 2016 simulation error is higher than the acceptable value $\left(1.0 \mathrm{gN} / \mathrm{m}^{3}\right)$.

At the last stage of this study, the calibrated ASM3 model of Bialystok WWTP was validated with the data set prepared for the period of January - July, 2017 (Figure 4).

The results of validation illustrated in Figure 4 show that the calibrated ASM3 model has an acceptable accuracy of predictions (all simulation points, except January 2017, have prediction error lower than $1.0 \mathrm{gN} / \mathrm{m}^{3}$ ), although it should be also noticed that default ASM3 model is able to predict effluent TN concentrations with similar or even better precision. This ambiguity may be explained by the uncertainty underlying modeling process based on scarce input data sets with limited informative value. For example, in this study the average monthly observations were estimated on the basis of two samples only, collected in different time intervals. In such a case, the input data used for the calibration and valida-

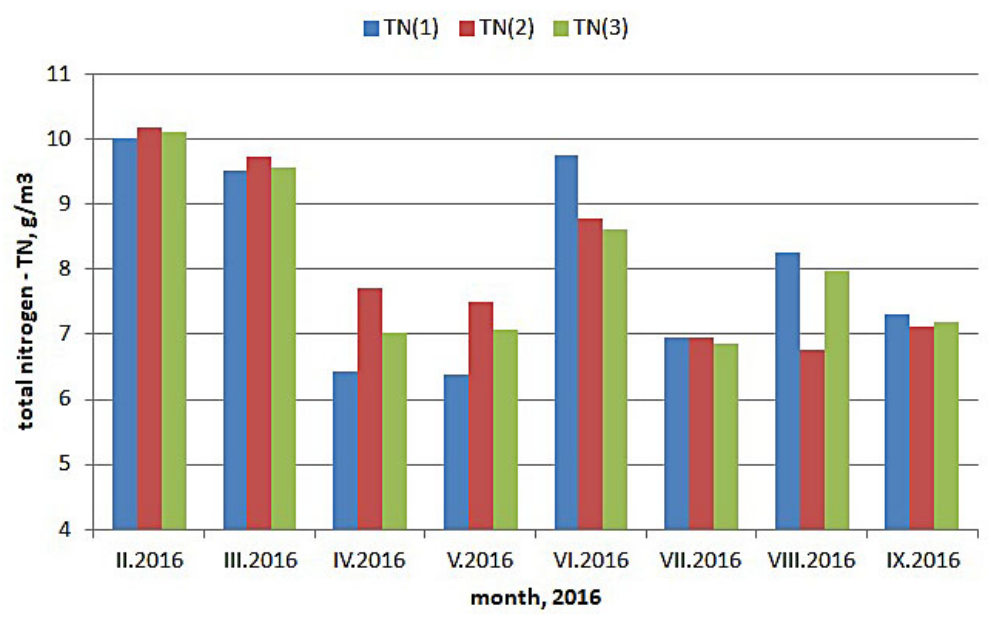

Figure 3. Comparison of observed and simulated effluent TN (total nitrogen) concentrations; TN(1) - observed, $\mathrm{TN}(2)$ - simulated with default ASM3 model, TN(3) - simulated with calibrated ASM3 model 
Table 3. Sensitivity analysis and calibration results for ASM3 model parameters

\begin{tabular}{|l|c|c|c|c|}
\hline \multicolumn{1}{|c|}{ Parameter } & \multirow{2}{*}{ Default value } & \multicolumn{2}{|c|}{ Sensitivity coefficient $\left(\mathrm{S}_{\mathrm{ij}}\right)$} & \multirow{2}{*}{$\begin{array}{c}\text { Calibrated } \\
\text { value }\end{array}$} \\
\cline { 3 - 5 } & & $\mathrm{NO}_{\mathrm{x}}$ & $\mathrm{N}-\mathrm{NH}_{4}$ & \multirow{2}{*}{0.065} \\
\hline $\begin{array}{l}\text { (s) Anoxic storage of dissovled species. with regard to } \\
\text { dinitrogen and nitrate }\left(\mathrm{x}_{3}\right) ;-\end{array}$ & 0.07 & 0.42 & 2.71 & \\
\hline (k) Autotrophic maximum growth rate $\left(\mathrm{m}_{\mathrm{A}}\right) ; \mathrm{d}^{-1}$ & 1.00 & 0.44 & 8.08 & 1.2 \\
\hline (k) Aerobic endogenous respiration rate $\left(\mathrm{b}_{\mathrm{A} . \mathrm{O} 2}\right) ; \mathrm{d}^{-1}$ & 0.15 & $<0.25$ & 2.17 & 0.15 \\
\hline
\end{tabular}

(s) - stoichiometric parameter; $(\mathrm{k})$ - kinetic parameter

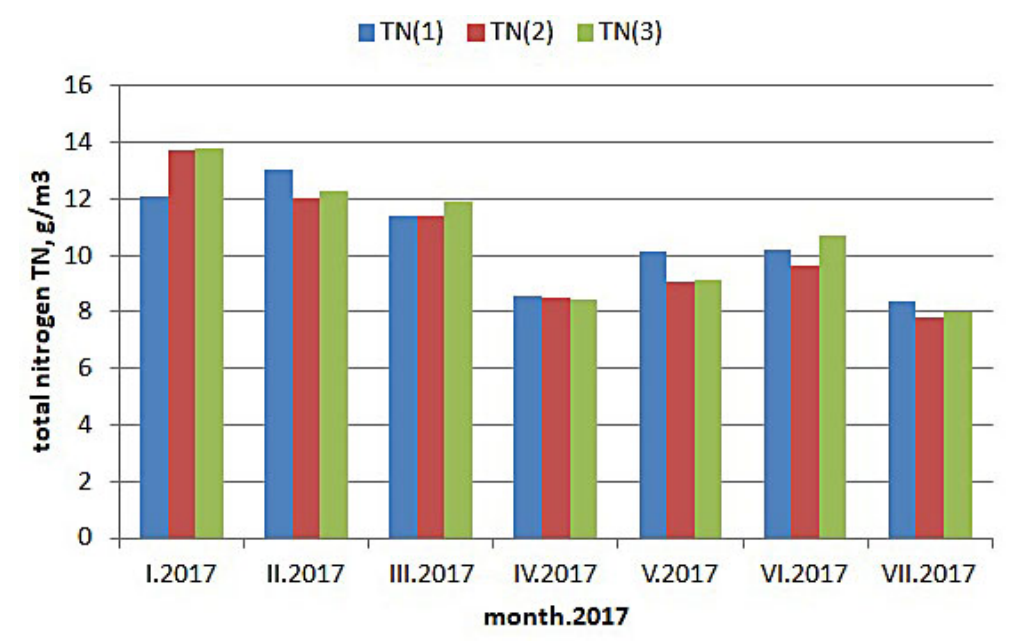

Figure 4. Results of ASM3 model validation for effluent total nitrogen (TN); TN(1) - observed, TN(2) - simulated with default ASM3 model, TN(3) - simulated with calibrated ASM3 model

tion of the model are very sensitive to the "noise" related with possible temporary disturbances in the process (like diurnal variations in hydraulic and contaminants load, operational errors, equipment failures etc.). The other factor that may influence the accuracy of model predictions in this work is related with specific mode of operation of Bialystok WWTP, which is focused on maximizing nitrogen removal by regulation of internal recirculation of nitrates rate, RAS rate and wasted sludge rate, depending on the current needs (in other words - sludge age is not a target operational parameter for the plant). Thus, the mass balance of microorganism in biological reactors, which is one of key components deciding about ASM quality, could not be verified during this study and sludge age values used in the model were not calculated from the measured data, but assumed on the basis of expert knowledge.

\section{CONCLUSIONS}

The research presented in this paper was performed on the Bialystok WWTP with the focus on applicability of limited data sets coming from standard plant monitoring program, for mathematical modeling of activated sludge process using the available ASM simulators. The obtained results allow for drawing the following conclusions:

1. Scarce data sets available from standard monitoring of WWTP performance may be used for setting up a facility model and for simulations of plant performance under steady state conditions;

2. Calibration of the Bialystok WWTP ASM3based model with the available data represented by monthly averaged values and with regard to nitrogen compound removal process, significantly improved the accuracy of model predictions for a considered time period,

3. There is no significant difference between the accuracy of predictions for the calibrated and default ASM3 plant model for the validation period, which indicates that the created model is not reliable enough and modeling results should be studied and implemented with a special care and awareness of uncertainty underlying the whole modeling procedure;

4. Improvement of the model reliability is possible, but additional data allowing for mass balance completion should be available; 
5. Despite the existing limitations and deficiencies of the model developed in this study, it can still be useful for various purposes, including: plant operators training (observation of plant response to the changes in basic operational parameters like recycle flows, anoxic to aerobic volume ratio; dissolved oxygen concentration etc., with regard to varying input characteristics), development of optimum control strategy, etc.

\section{Acknowledgements}

The authors highly appreciate the cooperation within this study with the Białystok Waterworks Ltd. (Wodociągi Białostockie Sp. z o.o.). We would like to especially thank the Chief Technologist of Bialystok WWTP, Mr Grzegorz Simson, who delivered invaluable information on the technological process.

The paper was accomplished under BUT Rector's grant S/WBIIS/2/14, supported by Polish Ministry of Science and Higher Education

\section{REFERENCES}

1. Barker P.S. and Dold P.L. 1997. General model for biological nutrient removal activated sludge systems: model presentation. Water Environment Research, 69(5), 969-984.

2. Çinar Ö., Daigger G.T., Graef S.P. 1998. Evaluation of IAWQ Activated Sludge Model No. 2 using steady-state data from four full-scale wastewater treatment plants. Water Environ. Res., 70 (6), 1216-1224.

3. Gujer W., Henze M., Mino T. and van Loosdrecht M.C.M. 1999. Activated Sludge Model No. 3. Water Science and Technology, 39(1), 183-193.

4. Hauduc H., Gillot S., Rieger L., Ohtsuki T., Shaw A., Takács I. and Winkler S. 2009. Activated sludge modelling in practice - An international survey. Water Science and Technology, 60(8), 1943-1951.

5. Hauduc, H., Rieger, L., Ohtsuki, T., Shaw, A., Takács, I., Winkler, S., Héduit, A., Vanrolleghem, P.A. and Gillot, S. 2011. Activated sludge modelling: Development and potential use of a practical applications database. Water Science and Technology, 63(10), 2164-2182.

6. Henze, M.; Grady, C.P.L.; Gujer, W.; Marais, G.V. R.; Matsuo, T. 1987. Activated Sludge Model No. 1; IAWPRC Scientific and Technical Report No. 1; International Association on Water Pollution Research and Control: London, U.K.

7. Henze, M.; Gujer, W.; Mino, T.; Matsuo, T.; Wentzel, M.C.; Marais, G.V.R. 1995. Activated Sludge
Model No. 2; IAWQ Scientific and Technical Report No. 3; International Association on Water Quality: London, U.K.

8. Henze, M.; Gujer, W.; Mino, T.; Matsuo, T.; Wentzel, M.C.; Marais, G.V.R.; van Loosdrecht, M.C.M. 1999. Activated Sludge Model No. 2d, ASM2d. Water Sci. Technol., 39 (1), 165-182.

9. Henze, M., Gujer, W., Mino, T. and van Loosdrecht, M.C.M. (Eds), Activated sludge models ASM1, ASM2, ASM2d and ASM3. Scientific and Technical Report No. 9, IWA Publishing, London, UK

10. Hulsbeek, J.J.W.; Kruit, J.; Roeleveld, P.J.; van Loosdrecht, M.C.M. 2002. A Practical Protocol for Dynamic Modeling of Activated Sludge Systems. Water Sci. Technol., 45 (6), 127-136.

11. Ignatowicz, K., Piekarski, J., Kozłowski, D. 2015. Wspomaganie procesu denitryfikacji preparatem Brenntaplus VP1 jako zewnętrznym źródłem węgla. Rocznik Ochrona Środowiska, 17, 1178-1195.

12. Langergraber, G.; Rieger, L.; Winkler, S.; Alex, J.; Wiese, J.; Owerdieck, C.; Ahnert, M.; Simon, J.; Maurer, M. 2004. A Guideline for Simulation Studies of Wastewater Treatment Plants. Water Sci. Technol., 50 (7), 131-138.

13. Liwarska-Bizukojc, E.; Biernacki, R. 2010. Identification of the most sensitive parameters in the activated sludge model implemented in BioWin software. Bioresource Technology 101 (19): 7278-7205.

14. Melcer, H.; Dold, P. L.; Jones, R. M.; Bye, C. M.; Takacs, I.; Stensel, H. D.; Wilson, A. W.; Sun, P.; Bury, S. 2003. Methods for Wastewater Characterization in Activated Sludge Modeling; Water Environment Research Foundation: Alexandria, Virginia.

15. Petersen B., Gernaey K., Henze M. and Vanrolleghem P. A. 2002. Evaluation of an ASM1 model calibration procedure on a municipal-industrial wastewater treatment plant. Journal of Hydroinformatics, 4(1), 15-38.

16. Petersen, B., Gernaey, K., Henze, M., Vanrolleghem, P.A. 2003. Calibration of activated sludge models: a critical review of experimental designs. In: Agathos, S.N., Reineke, W. (Eds.), Biotechnology for the Environment: Wastewater Treatment and Modelling. Waste Gas Handling. Kluwer Academic Publishers, Dordrecht.

17. Rieger L., Koch G., Kühni M., Gujer W. and Siegrist H. 2001. The EAWAG Bio-P module for activated sludge model No. 3. Water Research, 35(16), 3887-3903.

18. Rieger, L.; Gillot, S.; Langergraber, G.; Ohtsuki, T.; Shaw, A.; Takács, I.; Winkler, S. 2013. Guidelines for Using Activated Sludge Models; IWA Scientific and Technical Report No. 22; IWA Publish- 
ing: London.

19. Roeleveld, P.J.; van Loosdrecht, M.C.M. 2002. Experience with Guidelines for Wastewater Characterization in The Netherlands. Water Sci. Technol., 45 (6), 77-87.

20. Simson G. 2008. Pierwsze doświadczenia - test technologiczny z zastosowaniem preparatu BRENNTAPLUS VP1 jako zewnętrzne źródło węgla organicznego do intensyfikacji procesu denitryfikacji w Białostockiej Oczyszczalni Ścieków. Forum Eksploatatora 44 (6), 21-23.

21. Sochacki A., Knodel J., Geissen S.-U., Zambarda V., Bertanza G., Plonka L. 2009. Modelling and simulation of a municipal WWTP with limited operational data. Proceedings of a Polish-Swedish-Ukrainian Seminar, 2009; available online at: https://www.kth.se/polopoly fs/1.650929!/JPSU16p47.pdf (accesed January, 2017)

22. US EPA 1987. QUAL2E - The Enhanced Stream Water Quality Model EPA/823/B-95/003. Environmental Research Laboratory, Athens, GA, USA.

23. Vanrolleghem, P. A.; Insel, G.; Petersen, B.; Sin, G.; De Pauw, D.; Nopens, I.; Weijers, S.; Gernaey, K. 2003. A Comprehensive Model Calibration Procedure for Activated Sludge Models. Proceedings of the 76th Annual Water Environment Federation Technical Exhibition and Conference [CD-ROM]; Los Angeles, California, Oct 11-15; Water Environment Federation: Alexandria, Virginia.

24. Water Environment Federation: Wastewater Treatment Process Modeling, MOP31, 2 ${ }^{\text {nd }}$ Edition 2014. McGraw-Hill Professional, 2014, AccessEngineering. 